\title{
Historic Background for CSM's Nature and Human Values
}

\author{
Ronald V. Wiedenhoeft \\ Colorado School of Mines (CSM)
}

Since no university operates in a vacuum, developments in the academic community and society generally always stimulate changes in curricular emphases of specific institutions. Ecology is one of those "ideas in the air" that in recent years has fostered many new programs and courses. A few key dates and their major impulses are

- 1969, the establishment of the US Environmental Protection Agency;

- 1972, the first United Nations Conference on the Environment and Development (in Stockholm);

- 1987, the year of "Our Common Future," the report of the World Commission on Environment and Development (the "Brundtland Report");

- 1992, the second United Nations Conference on the Environment and Development (in Rio de Janeiro, the "Earth Summit").

The purpose of this paper is to examine ideas in the broader community that led CSM's Division of Liberal Arts and International Studies (LAIS) to formulate a new freshman core-curriculum course entitled "Nature and Human Values."

Not to be overlooked are the impulses that come to engineering schools through ABET's (Accreditation Board for Engineering and Technology) Engineering Criteria 2000. ${ }^{1}$ Among the most relevant mandates from $\mathrm{ABET}$ are the following three.

- an understanding of professional and ethical responsibility

- the broad education necessary to understand the impact of engineering solutions in a global and societal context

- a knowledge of contemporary issues

For engineering programs that include the word "environmental" in their title, ABET mandates the following goals, among otohers.

- knowledge of fundamental concepts of waste minimization and pollution prevention

- understanding of the roles and responsibilities of public institutions and private organizations in environmental management

- capability to apply environmental systems and process modeling techniques.

Clearly there is new interest and stimulus to apply technology to saving the environment.

\section{Devising Ecologically Conscious Mission Statements}

Thus, one of the most striking changes in recent university mission statements has come to be an emphasis on ecological consciousness and responsibilities of engineers to be effective stewards of the Earth and its resources. The change is all the more striking in engineering programs that historically have emphasized extraction of the Earth's minerals and energy resources, i.e., not an inherently ecological process. An almost revolutionary new mission statement of Colorado School of Mines pays homage to ecology in stating the following principles. 
1. We believe that the world faces a crisis in balancing resources availability with environmental protection and that CSM and its programs are central to the solution to that crisis.

2. Our education and research are dedicated to improve the quality of life of the world's inhabitants.

3. CSM is dedicated to educating students to become good stewards of the Earth and its resources.

4. CSM is committed to the mitigation of environmental damage caused by the production and utilization of minerals, energy, and materials, and to the development of processes that will minimize such damage in the future.

5. It is further committed to the development of technologies that can reduce the world's dependence on non-renewable resources.

6. CSM students should have the ability to self-educate, to continue to learn, both in their major field and in new areas.

7. They should possess the critical and creative thinking abilities to solve complex, open-ended problems with non-technical constraints.

8. They should be able to communicate effectively in writing as well as orally. In addition, they should be graphics- and computer literate.

\section{Liberally Educating Engineers or "Civilizing the Plumbers"2}

Characteristic of the historic split that evolved between the "two cultures," i.e., between technology and everything else, was an attitude that engineers were cultural boors, capable of crunching numbers but insensitive to the finer things of life. In keeping with a noble ambition of producing "well-rounded" graduates, many universities long ago found that a certain number of core and distribution courses outside students' areas of specialization should be mandated. For engineers this often meant taking a few courses in areas of the humanities and social sciences. In at least one school, the process of requiring a bit of literature here and perhaps a bit of music or art history there came to be known as "civilizing the plumbers." Since the results were usually less than fully satisfactory, in more recent years greater breadth and depth of liberal learning has been stressed as important for engineers. Striking a powerful chord for the integration of liberal learning into engineering education, CSM's new mission statement says that its graduates "should, through familiarity with humanities and social sciences, learn the world's complexities beyond their own set of givens, gain an appreciation of other people's values and ways of doing things, think effectively about ethical and social issues, and make conscious choices based on positive values."

In other words, the "freedom" at the root of liberal education implies liberation from the givens of one's conventional, accustomed cultural habits. A student's hoary argument that "I didn't come to an engineering school to study English and humanities!" no longer holds water. Refuge from the complexities of human nature and human societies should no longer be offered in engineering schools. Perhaps century-long efforts to integrate liberal learning are finally bearing fruit. As Samuel Florman tells us,

"For more than a hundred years educators have been trying to find an appropriate place for liberal learning in the engineering curriculum. Many of the good things that Americans think of when they speak of a college education are taught through the humanities and social sciences: knowledge of our history, government, and communal aspirations; 
awareness of the complexities of human nature and human societies; facility with language and appreciation of the arts.",

But knowledge limited to our own society and even to the broader Western tradition may still leave students too myopic. Today, learning how people, societies, and systems of all kinds work implies going beyond the obvious, developing not only understanding but appreciation for the validity of entirely different sets of values. Hence Western Civilization courses are frequently replaced by Global Civ, or at least Western Civ in a Global Context. Inevitably this process must include a critical look not only at negative as well as positive impacts of modern technology on the world and its peoples, but also at the downsides of imperialism of all colors. One of the great challenges of "civilizing the plumbers" today is to get engineers to accept willingly that there are, indeed, other, very valid paradigms to be seriously considered.

\section{Finding A New Paradigm}

Anticipating the argument that "Humanities is just another way of looking at things. Why should it be any more valid than any other paradigm?" seems worthwhile. It helps to have a chemical engineer, such as Ronald Nelson, provide an answer to "Why Engineers Should Study the Humanities." Not only does he encourage engineers to question and challenge their established beliefs, he holds out the prospect of having contact with philosophy develop more valid ways of reasoning. Humanities classes, he says, "should stimulate and stretch the mind." William Bennett, in his To Reclaim a Legacy, reiterates some of the great, fundamental questions of all time that, presumably, engineering students have seldom found raised in traditional curricula. "What is justice? What should be loved? What deserves to be defended? What is courage? What is noble? What is base? Why do civilizations flourish? Why do they decline? What can I know? What should I do? What may I hope for?"5

The essence of the new paradigm lies precisely in raising such questions and earnestly grappling with possible answers. Not a new dogma is thereby defined, but a new intensity and breadth of searching, a new open-mindedness, new awareness. An engineering student's concerns need to go far beyond one's own immediate interests and the interests of one's group.

Tendencies to seek authoritative answers have always been strong in engineering schools. Perhaps the greatest comfort of technology is believing that someone in the know will be able to solve everything and reduce uncertainties. As the revered Charles Frankel phrased it,

"Instead of waiting passively for a powerful and good authority to step in and fix everything up —or feeling helpless, incompetent and at the mercy of a conspiracy of evil authorities-[students of liberal arts] would be aware of limitations, that authority is neither a beneficent parent nor an evil demon, but rather a human being of mixed will, constrained by ability and the situation. Meanwhile they would recognize the complexity of their own emotions, surmount the temptations of passivity, rage or flight from the world as it really is, working and loving — with energy and commitment—for self, for others and for the larger society.",

Can we imagine how much of a change in the culture of engineering such a transformation in attitude would bring? 


\section{Understanding Society's Impacts}

The American Association of Colleges says it for everyone: "So many technical problems are now also social problems - or ethical, or political, or international problems - that some ability to deal with them as such is just part of the essential professional equipment of engineers." 7 The Association also points out that, in order to be able to do their work, engineers need to be able to convince non-engineers that what they recommend is worthwhile. Increasingly, we are told, technical projects are routinely designed by multidisciplinary teams, and those making or influencing decisions are likely to include legislators, members of the media, bureaucrats, and consumers.

University programs in Science, Technology, and Society (STS) demonstrate efforts to integrate seemingly disparate disciplines, but also show willingness to challenge traditional ways of assessing technical, economic, social, and ecological changes engineers bring about. When the United Nations Earth Summit of 1992 has heads of state and heads of government representing ninety-eight percent of the world's population signing an agenda for the twenty-first century, impacts on curricular planning ought to be profound. Agenda 21 and "The Rio Declaration" (1992) — and the pronouncements of the Earth Summit plus Five in New York in June of 1997_ are not the statements of radical fringe groups, nor are they merely vague statements of intent. Concepts in these documents demand rethinking our patterns of development and, hence, of engineering education. Among them is Principle 8 of the Declaration: "To achieve sustainable development and a higher quality of life for all people, States should reduce and eliminate unsustainable patterns of their production and consumption and promote appropriate demographic policies." " Recognizing society's impact on the Earth and engineering's impact on both society and the Earth must fundamentally influence premises of engineering education.

Collett and Karakashian in their Greening the College Curriculum, summarize the need for curricular changes: "Human behavior is responsible for our planet's current predicament, and only a change in the way we think and act can begin to repair the damage and avoid future depredations." ${ }^{, 9}$ Many college and university faculty are currently responding to this educational challenge.

\section{Fostering International Cooperation}

As Agenda 21 amply demonstrates, economic and ecological problems of the late twentieth century require unprecedented international cooperation if our capacity for sustainable development is to be realized. Growing resource consumption among the haves in face of a rapidly growing world population of the have-nots can only lead to drastic conflicts. Dealing constructively with interdependence on Spaceship Earth is crucial. Two additional principles of the Rio Declaration are "War is inherently destructive of sustainable development," and "Peace, development and environmental protection are interdependent and indivisible." The least we must do is foster international cooperation in engineering curricula. Joseph Bordogna proposes one promising way of doing so:

"A small adjustment within this new [liberal-studies] educational atmosphere could reap some strong universal benefits across all engineering curricula. Suppose, for example, that year-long courses combining language with culture were developed for the several 
principal cultural regions of the world. These courses would dwell on the origins of cultural development in those regions and would generate an appreciation for the values (social, political, financial, family, military, religious, technological, philosophical, etc.) enjoyed by each."10

Much more needs to be done toward developing understanding and empathy for other peoples' predicaments. Curricula emphasizing ecology and sustainability hold great promise in "free[ing] students from unexamined assumptions," as Nannerl Keohane says, "opening horizons from narrow parochialism onto the wide, wide world... a tolerance for ambiguity and complexity, an ability to be at ease with suspended judgment when closure would be premature."11

\section{Developing Ethical Values}

Perhaps the most controversial aspect of education in recent decades has been the matter of teaching ethics or "intellectual virtue," which, to avoid problems, seem simply to be ignored. As Russell Kirk, then President of the University of California system, pointed out, contemporary education systems all deal little with the "ordering of the soul and ordering of the commonwealth." 12 Business school approaches, critiqued by Paul Wilkes, might be analogous to those in engineering:

"We were producing excellent managers, but we had frankly not paid attention to what kind of people they would be.... We were so concerned with economic self-interest, so enamored of exciting new concepts, for instance Japan's just-in-time delivery. Maybe we were hoping for just-in-time values.", 13

At any rate, current educational leaders seem once again willing to transcend value-neutral education and rediscover cultivation of conscience, as well as of reason and imagination. Perhaps it will again be perceived as important to stimulate students' examination of "fortitude, prudence, temperance, justice, faith, hope, charity," as Kirk would have us do. Addressing problems of environmental degradation and unsustainable development may provide the critical mass that brings ethical issues to the fore. One of the purposes of dealing with ethics in the revised core curriculum at Harvard, as another example, is "to show students that it is possible to think systematically about such issues as justice, obligation, personal responsibility, citizenship, and friendship." Consciously analyzing the whole pattern of relationships among humans, all other organisms, and the entire biosphere that is our home-in other words, ecology-requires coming to grips with ethical values.

\section{Achieving Changed Behavior}

One measure of success in education would be to evaluate the changes in behavior it causes. Five norms for an ideal campus, as articulated by Charles Muscatine, suggest ways in which both students and faculty may need to modify their behavior.

1) It should produce students who are self-motivated inquirers.

2) Its studies should be focused on sustaining the future of the human endeavor in a livable environment.

3) It should be composed of a multicultural community.

4) It should provide a protected environment for educational research and development. 
5) It should be committed to self-assessment, regularly testing how well faculty members are getting their ideas across to students. ${ }^{14}$

Which changes in behavior are required of students, faculty, administrators and others interested in quality engineering education, in order to attain this ideal? Curriculum revisions currently underway at many universities promise answers to that question. At Colorado School of Mines, awareness of these issues stimulates an ongoing search for better ways to have liberal learning impact on engineering education. Currently CSM's entire undergraduate curriculum is undergoing re-examination. As one part of that process, the Division of Liberal Arts and International Studies is piloting its freshman core course, "Nature and Human Values," as described elsewhere in this report by my colleagues. Its main content deals with environmental ethics and our ecological footprint, enabling interdisciplinary approaches regarding two major questions:

1) How does Nature affect both quality of human life and the formulation of human values and ethics?

2) How do human actions, values, and ethics affect Nature?

Among themes included are population, natural resources, stewardship of the Earth, and the future of human society. As the first of a series of new core courses taking a systems approach, Nature and Human Values plays a key role in defining new patterns of acting and thinking among engineers. We aspire to make it a worthy conveyor of inspiration and insight from our many predecessors who sought to integrate liberal arts and international studies with technology.

\section{References}

1. See www.abet.org/EAC/eac2000.html

2. Kranzberg, Melvin. "Educating the Whole Engineer," ASEE Prism, vol. 3, no. 3, November 1993, 29.

3. Florman, Samuel C. "Learning Liberally.” ASEE Prism, vol. 3, no. 3, November 1993, 18-23.

4. Nelson, Ronald E. "Why Engineers Should Study the Humanities," Chemical Engineering, Sept. 28, 1987.

5. Bennett, William J. "To Reclaim a Legacy: A Report on the Humanities in Higher Education." National Endowment for the Humanities (typescript version), November 1984, 5

6. Frankel, Charles. "The Academy Enshrouded," National Humanities Center Challenge, December 1977.

7. Association of American Colleges. An Engineering Student's Guide to the Humanities \& Social Sciences. Washington, D.C.: 1988.

8. "The Rio Declaration (1992)," reprinted in Pojman, Louis P., editor. Environmental Ethics: Readings in Theory and Application. Sudbury, MA: Jones and Bartlett, 1994, 501-03.

9. Collett, Jonathan, and Karakashian, Stephen. "Turning Curricula Green," The Chronicle of Higher Education, Feb. 23, 1996. Their book is Greening the College Curriculum: A Guide to Environmental Teaching in the Liberal Arts. Washington, DC: Island Press, 1996.

10. Bordogna, Joseph. “The Cultural Connection.” conference presentation typescript, n.d., ca. 1986. 
11. Keohane, Nannerl O. "Creativity, the Classics, and the Corporation." conference presentation typescript, September 1986.

12. Kirk, Russell. "Traditions of Thought and the Core Curriculum," photocopy from an anthology. 1986.

13. Wilkes, Paul. "The Tough Job of Teaching Ethics: Harvard's M.B.A. students find ethics can get murky." The New York Times, Jan. 22, 1989, 1 \& 24.

14. Muscatine, Charles. Chair of the "New Campus Group" of the University of California System. Quoted in Karen Grassmuck, "For U. Of California, a Chance to Create $21^{\text {st }}$-Century Campuses From Scratch," The Chronicle of Higher Education, Sept. 12, 1990.

RONALD V. WIEDENHOEFT is professor of liberal arts and international studies at Colorado School of Mines. Author of Cities for People: Practical Measures for Improving Urban Environments, he was Fulbright visiting professor at the Technical Universities of Vienna and Graz, Austria, in 1994-95 